\title{
Complete cavopulmonary shunt completion after in utero balloon atrial septoplasty for hypoplastic left heart syndrome
}

\author{
Nicholas H. Von Bergen, MD, ${ }^{a}$ Harold M. Burkhart, MD, ${ }^{b}$ Larry A. Latson, MD, ${ }^{c}$ Stephen P. Emery, MD, ${ }^{d}$ \\ Adel K. Younoszai, MD, ${ }^{e}$ and Heather L. Bartlett, MD, ${ }^{a}$ lowa City, lowa, Rochester, Minn, Cleveland, Ohio, Pittsburgh, Pa, \\ and Denver, Colo
}

耳 ypoplastic left heart syndrome (HLHS) with intact or restrictive atrial septum is associated with mortality as high as $50 \%$ to $80 \% .^{1,2}$ There is a theoretical benefit to in utero creation of an atrial septal defect, although to date this procedure has been associated with a high mortality without conclusive improvement in survival or alteration of hemodynamics. ${ }^{1,3}$ We describe the case of a patient successfully treated by in utero atrial septostomy who subsequently progressed through the complete cavopulmonary shunt procedure. To our knowledge, this is the first such case to be described in the literature.

\section{Clinical Summary}

Prenatal history. At 20 weeks' gestation, a fetal echocardiogram demonstrated severe aortic stenosis with minimal antegrade flow and a dilated, poorly contractile left ventricle. Four weeks later there was progression to HLHS. No interatrial flow could be demonstrated and the pulmonary venous flow pattern was consistent with severe obstruction (Figure 1).

In utero atrial septostomy. At 28 weeks' gestation, the patient was evaluated for fetal intervention. After discussion with the involved services, the mother wished to proceed with attempted fetal intervention but declined laparotomy. Under epidural anesthesia, septoplasty was unsuccessful owing to poor fetal orientation and borderline ultrasonic visualization. The fetus tolerated the procedure well but had a pleural effusion that resolved over the next 10 days. At 30 weeks' gestation, the mother agreed to a

From the Department of Pediatric Cardiology, the University of Iowa Children's Hospital, ${ }^{a}$ Iowa City, Iowa; Department of Cardiovascular Surgery, the Mayo Clinic, ${ }^{\mathrm{b}}$ Rochester, Minn; Department of Pediatric Cardiology, the Cleveland Clinic, ${ }^{\mathrm{c}}$ Cleveland, Ohio; Department of Obstetrics, Gynecology \& Reproductive Sciences, the University of Pittsburgh, ${ }^{\mathrm{d}}$ Pittsburgh, Pa; and Department of Pediatric Cardiology, the Denver Children's Hospital, ${ }^{\mathrm{e}}$ Denver, Colo.

Larry A. Latson, MD, reports lecture fees from Medtronic and W. L. Gore and grant support from NMT Medical and W. L. Gore.

Received for publication July 9, 2007; accepted for publication July 19, 2007.

Address for reprints: Nicholas H. Von Bergen, MD, The University of Iowa Children's Hospital, 200 Hawkins Dr, Iowa City, IA 52242 (E-mail: Nicholasvonbergen@uiowa.edu).

J Thorac Cardiovasc Surg 2007;134:1355-6

$0022-5223 / \$ 32.00$

Copyright () 2007 by The American Association for Thoracic Surgery

doi:10.1016/j.jtcvs.2007.07.033 second attempt under general anesthesia, with a laparotomy if needed. The procedure was performed under general anesthesia. A laparotomy was required to yield adequate fetal positioning. Through direct manipulation, the fetus was maneuvered into position for placement of a 19-gauge thin-walled needle through the uterine wall, the fetal thorax, the right atrial wall, and the atrial septum into the fetal left atrium. Static balloon septoplasty was performed with three balloon inflations (maximum of $4 \mathrm{~mm}$ ), and a jet of low-velocity left-to-right flow could be seen on color Doppler (Figure 2).

Follow-up fetal echocardiograms demonstrated continued patency of the atrial septal defect. Pulmonary venous flow velocity initially normalized and then subsequently showed a mildly restrictive pattern (Figure 1).

Postnatal hospital course. Postnatally, the patient's diagnosis of HLHS was defined with poor right ventricular function and a restrictive atrial septum. He was in relatively stable condition immediately after birth and underwent balloon atrial septostomy at about 36 hours of age for a mean interatrial gradient of $21 \mathrm{~mm} \mathrm{Hg}$. He subsequently underwent Norwood palliation 6 days after birth. This involved aortopulmonary anastomosis with arch reconstruction, a 6-mm polytetrafluoroethylene (Gore-Tex conduit; W. L. Gore \& Associates, Inc, Flagstaff, Ariz) conduit from the right ventricle to the pulmonary artery, and atrial septectomy. Intraoperatively, the atrial septum was noted to be markedly hypertrophic. There was no evidence of pericardial adhesions.

At 5 months of age, the patient successfully underwent a bidirectional cavopulmonary anastomosis and left pulmonary arterioplasty. Worsening cyanosis prompted complete cavopulmonary anastomosis with an $18-\mathrm{mm}$ extracardiac conduit and a repeat atrial septectomy at 24 months of age. The atrial septum had become restrictive again, with a mean gradient of 10 to 12 $\mathrm{mm} \mathrm{Hg}$. Six months after discharge, the patient continues to do well.

\section{Discussion}

HLHS, characterized by a small left ventricle and a hypoplastic aortic arch, is present in as many as 1 in 10,000 live births. ${ }^{4}$ Surgical palliation after birth is associated with a high morbidity and mortality even with the current surgical interventions. A significant risk factor, with a mortality of $50 \%$ or more, is an intact or restrictive atrial septum, resulting in left atrial hypertension and an increase in pulmonary venous pressure..$^{2,5}$ There are significant theoretical advantages to in utero palliation, including improved circulation and potential for improved structural and functional development. Therefore, fetal interventions including balloon ${ }^{1}$ or 


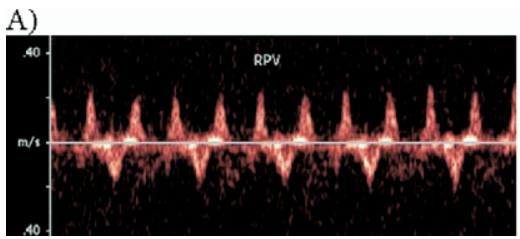

B)

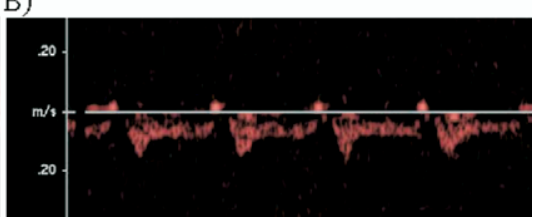

Figure 1. Right upper pulmonary venous flow patterns by Doppler ultrasound. A, Before septoplasty with a highly restrictive pulmonary venous flow pattern. B, After septoplasty with a normal pulmonary venous flow pattern.
A)
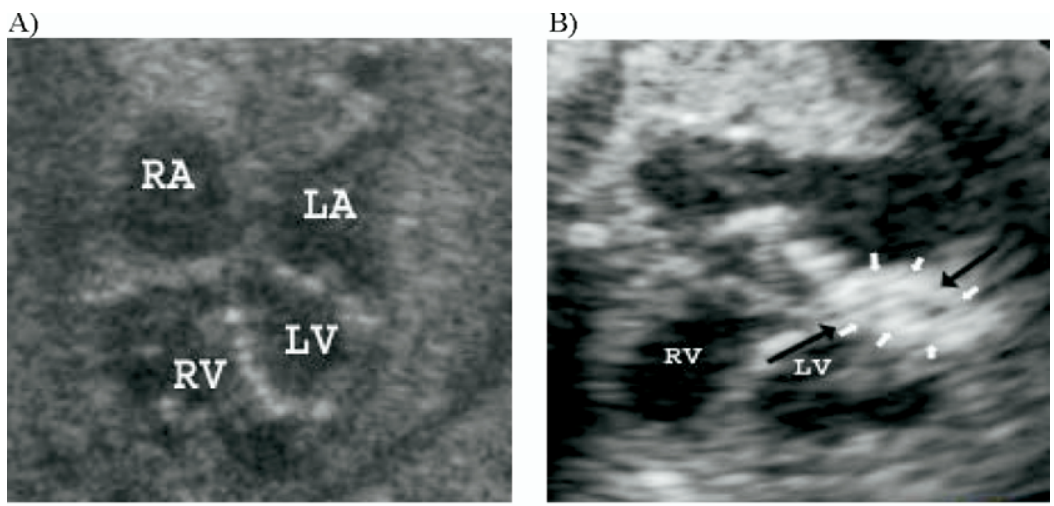

Figure 2. A, Fetal sonogram showing HLHS with intact atrial septum. B, In utero static balloon atrial septoplasty: The 4-mm balloon (white arrows) is inflated across the atrial septum (dark arrows.) C, Fetal echocardiogram 4 days after septostomy showing jet of left-to-right flow (large arrow) from the somewhat dilated left atrium $(L A)$ to the right atrium $(R A)$ through the newly created atrial septal defect. There is a small jet of mitral insufficiency (small arrow). LV, Left ventricle; $R V$, right ventricle.

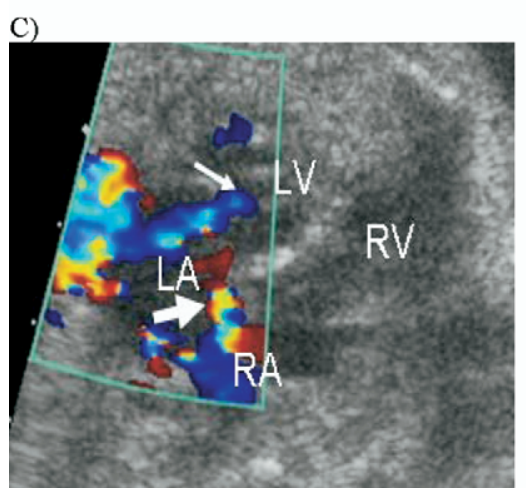

laser atrial septostomy ${ }^{3}$ have been pursued. Although some centers have shown improvement in the size of the interatrial communication by using fetal echocardiography, significant procedural mortality with variable clinical improvement has been seen in the earliest published results. ${ }^{1}$

\section{Conclusions}

HLHS with intact or restrictive atrial septum is associated with high mortality. There is a theoretical benefit to in utero creation of an atrial septal defect, although to date this procedure is associated with high mortality and there has been no conclusive improvement in survival or alteration of hemodynamics. To our knowledge, this is the first patient described in the literature who has undergone in utero atrial septostomy and completed the 3 palliative stages. Although results of this procedure have been variable, this palliation can potentially have a significant positive impact in select patients.

\section{References}

1. Marshall AC, van der Velde ME, Tworetzky W, Gomez CA, WilkinsHaug L, Benson CB, et al. Creation of an atrial septal defect in utero for fetuses with hypoplastic left heart syndrome and intact or highly restrictive atrial septum. Circulation. 2004;110:253-8.

2. Rychik J, Rome JJ, Collins MH, DeCampli WM, Spray TL. The hypoplastic left heart syndrome with intact atrial septum: atrial morphology, pulmonary vascular histopathology and outcome. J Am Coll Cardiol. 1999;34:554-60.

3. Quintero RA, Huhta J, Suh E, Chmait R, Romero R, Angel J. In utero cardiac fetal surgery: laser atrial septotomy in the treatment of hypoplastic left heart syndrome with intact atrial septum. Am J Obstet Gynecol. 2005;193:1424-8.

4. Ferencz C, Rubin JD, McCarter RJ, Brenner JI, Neill CA, Perry LW, et al. Congenital heart disease: prevalence at livebirth. the BaltimoreWashington Infant Study. Am J Epidemiol. 1985;121:31-6.

5. Vlahos AP, Lock JE, McElhinney DB, van der Velde ME. Hypoplastic left heart syndrome with intact or highly restrictive atrial septum: outcome after neonatal transcatheter atrial septostomy. Circulation. 2004;109:2326-30. 